\title{
A Escola na Promoção de Ações Voltadas à Doação
}

\section{School Promoting Actions toward Donations}

Luciana Karine de Souza' (orcid.org/0000-0001-9641-6163)

Sophia Beylouni Santos Martínez² (orcid.org/0000-0003-0048-7739)

\begin{abstract}
Resumo
A escola é promotora de desenvolvimento humano em todos os seus aspectos. Nesse sentido, tem envolvido os estudantes em ações que promovam tanto questões éticas relacionadas à justiça como à benevolência. O objetivo desse estudo é descrever as ações voltadas a campanhas de doação protagonizadas por escolas. Foram analisados os conteúdos de 49 postagens na Internet de campanhas de doação realizadas por escolas brasileiras. Entre os principais resultados, observou-se que $70 \%$ das escolas são da rede privada de ensino, a doação de sangue como o objetivo mais citado, uma estratégia não competitiva foi utilizada em quase todas as campanhas, com predominância do valor da solidariedade nos conteúdos analisados. Os resultados são interpretados com base em estudos nacionais e internacionais dedicados aos temas da doação, da generosidade e do desenvolvimento moral. São apresentadas recomendações voltadas para a criação e desenvolvimento de campanhas de doação protagonizadas por escolas.
\end{abstract}

Palavras-chave: Educação. Valores. Doação.

\begin{abstract}
The school context promotes human development in every aspect. Along these lines, it has engaging students in actions that foster ethical topics related to justice and benevolence. The objective of this study is to describe actions towards donation campaigns conducted by schools. We analyzed the contents of 49 Internet posts about donation campaigns made by Brazilian schools. Amongst the main results, we observed that: $70 \%$ of the schools are private, blood donation is the most frequent goal cited, a non-competitive strategy was utilized in nearly all campaigns, with predominance of the value of solidarity in the analyzed contents. Results are discussed alongside national and international studies dedicated to donation, generosity, and moral development. Recommendations are made to guide the creation and development of donation campaigns conducted by schools.
\end{abstract}

\footnotetext{
1 Universidade Federal do Rio Grande do Sul, Porto Alegre, Brasil. E-mail: luciana.karine@ufrgs.br. O presente estudo foi conduzido durante os estudos de pós-doutorado da primeira autora na Universidade Federal do Rio Grande do Sul (2013-2018) com o apoio do Programa de Pós-Graduação em Psicologia (PNPD/CAPES).

2 Universidade Federal do Rio Grande do Sul/Pontifícia Universidade Católica do Rio Grande do Sul, Porto Alegre, Brasil. E-mail: bsm.sophia@gmail.com.
} 
Keywords: Education. Values. Donation. 


\section{Introdução}

O objetivo principal do presente trabalho é descrever as ações voltadas a campanhas de doação protagonizadas por escolas. A pesquisa foi impulsionada por uma revisão de literatura sobre publicações nacionais no tema da doação (Souza \& Freitas, 2019) e pelo estudo de projetos em educação de valores desenvolvidos por escolas e relatados em Menin, Bataglia e Zechi (2013). Portanto, trata-se de um trabalho contextualizado com estudos psicológicos dedicados à moral, focalizando em um tema de pouca exploração científica em Psicologia no país.

Em Psicologia Moral, a justiça e a benevolência têm recebido extensa atenção dos pesquisadores (Biaggio, 1999). Nesse campo de estudos, a generosidade, do âmbito da benevolência, vem sendo estudada sistematicamente em amostras brasileiras principalmente por La Taille (2006). Um exemplo de ação generosa é a doação.

Segundo La Taille (2006), a generosidade se caracteriza por altruísmo, sacrifício e atenção à personalidade. $O$ ato generoso é direcionado a outrem, beneficiando, a priori, o beneficiário da ação; ele requer que o benfeitor (o que fez o bem, o doador) sacrifique algo de si; e, por fim, a doação precisa ser coerente a necessidades específicas do beneficiário. Tendo o autor identificado a generosidade em crianças de 6 anos de idade, concluiu que a generosidade, "por ser menos relacionada às imposições das figuras de autoridade do que as regras de justiça, e mais a relações sociais simétricas despertadas pela simpatia, ser produto de uma construção mais autêntica porque decorrente de relações de cooperação" (La Taille, 2006, p.16). Dessa maneira, o autor propõe que o ato generoso (por exemplo, doar) é valorizado antes do ato justo na infância.

$\mathrm{Na}$ Psicologia, quanto à benevolência, são dignas de nota as pesquisas desenvolvidas por Nancy Eisenberg sobre moralidade prósocial, altruísmo, empatia, generosidade, entre outros aspectos (Fabes \& Eisenberg, 1998; Eisenberg, Spinrad \& Morris, 2014). Em uma detalhada metanálise realizada por Fabes e Eisenberg (1998), com mais de uma centena de estudos empíricos sobre comportamento prósocial de pré-escolares até a adolescência, os autores conseguiram identificar que "à medida que as crianças avançam em idade, os comportamentos pró-sociais normalmente são mais propícios a ocorrer" (tradução livre, p.7). Provavelmente sim, mas o estudo de van Ijzendoorn,

Bakermans-Kranenburg, Pannebakker e Out (2010) mostra que algo mais é preciso.

Van Ijzendoorn et al. (2010) relataram uma série de estudos que investigaram o que mais pesa, em crianças, para estimular o comportamento de doar dinheiro para uma entidade mundialmente conhecida, como a Unicef: genética, fatores neurobiológicos, nível de apego, cuidado parental e aspectos situacionais. Este último foi o fator mais forte a conseguir provocar comportamentos de doação nas crianças analisadas: um gentil estímulo, por parte do experimentador, para que a criança 
doasse um pouco dos prêmios que conquistou, em jogos na situação experimental, para crianças famintas mostradas em uma propaganda da Unicef. De fato, o ser humano pode ter uma tendência considerável ao altruísmo, mas o que parece importante, a partir disso, é descobrir o que catalisa a demonstração da intenção em ação: do querer dar ao dar realmente, de fato.

Outro estudo, de Ongley, Nola e Malti (2014), sobre o comportamento de doar em crianças, encontrou que a ação de doar se mostrou mais fortemente associada a processos cognitivos de raciocínio sobre as necessidades dos outros, no caso, crianças pobres. Antes disso, a decisão por doar mostrou-se mais relacionada a sentimentos morais, como simpatia ou culpa. Assim, tomada a decisão, o comportamento requer maior investimento cognitivo para se realizar.

Um dos contextos privilegiados para o estímulo a comportamentos de doar é o escolar. A escola, como potencial promotora de desenvolvimento humano em todos os seus aspectos (físico-motor, cognitivo, afetivo, moral, social), tem envolvido os estudantes em ações que promovam tanto questões éticas relacionadas à justiça como à benevolência.

Menin et al. (2013) descreveram 13 projetos bem-sucedidos de educação em valores realizados em escolas públicas brasileiras. Em uma das escolas, localizada no interior de São Paulo, os estudantes ao longo do ano são motivados a arrecadar alimentos e remédios para doação a entidades de cuidado a crianças e a idosos.

Souza e Freitas (2019) relatam uma revisão de literatura sobre publicações nacionais que trataram do tema da doação. Todas as publicações, identificadas em bases de dados referenciadas, trataram da doação de órgãos, tecidos, sangue, leite humano, córneas, gametas e medula óssea. Nenhuma publicação tratou da doação de alimentos, brinquedos, agasalhos, medicamentos e assemelhados. As autoras mostraram que, além da raridade de publicações no tema, aquelas identificadas não tratavam de objetos mais fáceis de atingir em campanhas de doação que envolvam estudantes (no caso, objetos como brinquedos, roupas e alimentos, no lugar de sangue, etc.).

Outrossim, uma busca realizada fora do âmbito das revistas nacionais indexadas em bases de dados bibliográficas possibilitou a localização de quatro artigos que tratam da questão da doação envolvendo estudantes brasileiros do ensino fundamental e médio. Um apanhado desses trabalhos é apresentado a seguir.

Moraes, Gallani e Meneghin (2006) abordaram 94 estudantes do ensino médio (64 do sexo feminino), com idade entre 16 e 18 anos, sobre suas crenças com relação à doação de órgãos. Entre os principais resultados, os autores notaram uma crença favorável à doação de órgãos calcada na ideia de perdão dos pecados (referido por $85 \%$ dos participantes). Assim, o doador, ao concordar com a doação, teria os seus pecados perdoados ao doar seus órgãos.

Figueiredo e Comino (2014) relatam um projeto de extensão universitária desenvolvido em escolas do ensino fundamental há mais de 25 anos. O objetivo é conscientizar os alunos sobre a doação de sangue, preparando-os para uma 
escolha mais informada no futuro. $\mathrm{O}$ projeto utiliza recursos como fornecer informações sobre o sangue e o processo de doação, e envolver os alunos em atividades como jogos, assistir a desenhos e teatro de fantoches, participar de um concurso de frases e visitar o banco de sangue da cidade. Segundo os autores do relato, um terço dos pais dos alunos da escola já doou sangue, o que aponta para um efeito positivo do projeto sobre a comunidade local. O principal argumento de Figueiredo e Comino está em não esperar até o ensino médio para investir na conscientização sobre a doação de sangue nas escolas. O impacto sobre os pais das crianças estudantes é um dado que evidencia a eficácia do tipo de trabalho realizado. Ainda que seja insuficiente a idade dos alunos para doar sangue, o trabalho está adequado quanto a tratar do tema já nessa faixa etária, como argumenta La Taille (2006) sobre a generosidade.

Os trabalhos de Brandão, Mota e Pizzolato (2016) e de Schirmer et al. (2007) apresentam um levantamento da opinião de estudantes do ensino médio de escolas públicas e privadas sobre a doação de órgãos e tecidos. Enquanto no trabalho de Schirmer et al. (2007) $77 \%$ dos alunos do ensino privado e $63 \%$ do ensino público admitiram que doariam órgãos e tecidos, no estudo de Brandão et al. (2016) 76\% dos estudantes de escolas públicas e $54 \%$ das particulares não doariam. Com dados tão diversos, caberia investigar melhor o contexto escolar das instituições envolvidas, posto que projetos pontuais, como o referido em Menin $e t$ al. (2013), podem exercer influência sobre as opiniões dos adolescentes.
Nogueira et al. (2016) avaliaram os conhecimentos e opiniões de 47 adolescentes estudantes do ensino médio sobre doação de órgãos, antes e depois de uma ação educativa voltada ao tema. A idade dos estudantes variou de 13 a 17 anos, sendo 58\% mulheres. Um enfermeiro realizou uma explanação dialogada com os participantes sobre a questão da doação de órgãos, utilizando também os dados do questionário aplicado aos estudantes previamente ao seminário. Esse instrumento coletou dúvidas, ideias errôneas sobre a doação de órgãos e outros elementos utilizados pelo enfermeiro em sua explanação. A atividade durou em torno de $1 \mathrm{~h} 30 \mathrm{~min}$, seguida de um debate com os alunos para troca de ideias, esclarecimento de questões e dúvidas, etc. Terminado o debate, o mesmo questionário aplicado antes da atividade foi reapresentado aos alunos. Segundo os autores, o porcentual de dúvidas reduziu de $81 \%$ para $22 \%$. Muitas respostas sobre aspectos específicos do processo de doação de órgãos passaram de inadequadas para adequadas após a palestra. Além disso, relatam Nogueira et al. (2016) que a intenção de doar órgãos após a morte aumentou de 73\% para $87 \%$ depois do seminário. Estudos como esse evidenciam como palestras informativas, e avaliadas, podem trazer benefícios aos participantes quanto a conhecimentos importantes necessários para uma tomada de decisão informada com relação à doação de órgãos e tecidos.

Conhecidos os estudos que abordaram a doação em estudantes, interessou buscar estudos que mostrassem ações voltadas para doações, de qualquer natureza, protagonizadas por escolas. 
Não tendo sido encontrados resultados, criou-se o presente estudo, com o objetivo de conhecer como as escolas tratam, na prática, do tema da doação. Além disso, buscou-se investigar que tipo de valores estão conectados às ações de doação feitas por escolas.

Um estudo amplo realizado com escolas de todas as regiões do Brasil demonstrou que a coleta de informações diretamente com as escolas gera um baixo retorno de respostas (Menin et al., 2013). Dessa forma, para o presente trabalho, optou-se por coletar os dados diretamente publicados na Internet. Assim, o escopo dos dados foi delimitado àquelas escolas que, de alguma maneira, deram publicidade na Internet às ações realizadas em prol de doações por parte da própria escola.

\section{Método}

Utilizando-se o Google como ferramenta de busca, foi inserida a expressão “campanha doação escola 2015" no campo disponível pela plataforma. Selecionou-se o ano de 2015 para que a busca pudesse gerar resultados mais concentrados em um determinado segmento de tempo. Quanto aos termos escolhidos, buscou-se especificamente a intenção de campanha nas atividades, para que não gerassem resultados não relacionados com ações de doações. O termo escola foi inserido para que proporcionasse foco na seleção dos resultados. Ainda assim, milhares de resultados surgiram na tela, e optou-se pela análise das 20 primeiras páginas de resultados exibidas pela plataforma. A busca foi realizada em março de 2016.
A leitura dos resultados buscou as postagens pertinentes ao tema de pesquisa, descartados aqueles que não envolviam escola, que não foram protagonizados por escolas e que não tratassem de campanha de doação. Depois das exclusões, restaram 49 postagens para análise; todas foram copiadas na íntegra e coladas em um único arquivo de processador de texto.

A análise das 49 postagens seguiu as recomendações básicas para a codificação no contexto da análise qualitativa de dados, utilizando-se a técnica de codificação in vivo (Saldaña, 2011). Com essa técnica, como sugere o nome, os códigos são termos dos próprios dados. Por exemplo, se utilizada a palavra solidariedade, essa mesma palavra pode ser escolhida como um código, e unida a outras semelhantes para criar uma categoria (conjunto de códigos). A homogeneidade interna dos conteúdos nas categorias e a heterogeneidade intercategorias são critérios fundamentais na análise de conteúdos e expressamente seguidos na presente análise.

Cada caso foi categorizado por estado do Brasil, capital ou interior, escola pública ou particular, ano da doação, mês da doação, nível de ensino (infantil, fundamental, médio, e suas combinações), origem do site da notícia (escola, mídia, governo, outro), participantes da ação (alunos, professores, pais e combinações), objeto doado, parceria com instituições, organizações e governos, destino da doação, tipo de envolvimento dos alunos na ação, estratégia principal da ação, e valores referidos no texto sobre a ação de doação. Como visto, uma abordagem indutiva foi utilizada para a criação 
de categorias com unidades temáticas retiradas dos textos das postagens e agrupadas por semelhança. Dessa forma, são parte da descrição dos resultados as categorias criadas a partir dos dados em mãos.

Os dados coletados foram organizados em um banco de dados com uso do software Excel. As categorizações foram conferidas com um segundo avaliador, previamente treinado em análise qualitativa de conteúdos, para verificar a pertinência das categorias, sua coerência interna e claro discernimento de conteúdos entre o grupo de categorias em cada aspecto analisado. As divergências, ainda que poucas, foram dirimidas com base nas evidências consultadas no texto das postagens.

\section{Resultados}

Em primeiro lugar, são apresentados os dados que descrevem características das escolas envolvidas. Em segundo, as características das doações envolvidas nas campanhas. Cabe mencionar que dois casos identificados nos resultados são do ano de 2016. Optou-se pela não exclusão destes, já que os textos relatavam atividades ocorridas em 2015. Quanto à época do ano, 55\% das campanhas ocorreram entre os meses de setembro e dezembro.

A maioria dos sites que continha a notícia sobre a campanha de doação na escola era da própria escola ( $f=25$ ). Outros 13 sites eram de veículos de mídia (rádio, televisão, jornal, etc.), sete sites pertenciam a governos municipais ou estaduais e quatro eram de outra origem.
Foram identificadas escolas provenientes de 18 diferentes estados brasileiros. Dos 49 casos, 15 se referem a escolas do estado de São Paulo, sendo que a segunda maior frequência foi do estado do Ceará $(f=5)$. As demais frequências, em ordem decrescente, foram as seguintes: Espírito Santo $(f=4)$, Minas Gerais (3), Paraíba (3), Rio de Janeiro (3), Alagoas (2), Mato Grosso do Sul (2), Piauí (2) e Rio Grande do Sul (2). O Distrito Federal e os seguintes estados foram identificados uma vez no banco: Bahia, Goiás, Maranhão, Mato Grosso, Pernambuco, Paraná e Santa Catarina. No conjunto, foram 20 capitais e 29 cidades do interior dos estados.

Sobre o tipo de escola, notou-se a predominância de escolas particulares (70\%). Quanto ao nível de ensino das escolas, 17 delas abordam educação infantil, ensino fundamental e médio. Nove casos envolveram apenas escolas de ensino médio e oito casos com ensino fundamental e médio. Sete escolas são de ensino infantil e fundamental, seis de ensino apenas fundamental e duas somente de educação infantil.

As campanhas de doações, em sua maioria, tiveram como objetivo incentivar a doação de sangue (17 ocorrências). A Tabela 1 mostra as frequências dos resultados para o objeto principal da ação de doação. Foi chamado de objeto principal dado que algumas campanhas procuravam incentivar a doação de mais de um objeto, por exemplo, roupas e brinquedos. Assim, foi considerado o primeiro objeto mencionado nos casos em que se aplicaram mais de um tipo de doação. 
Tabela 1. Frequência dos tipos de doações citadas nas campanhas da amostra

\begin{tabular}{cc}
\hline $\begin{array}{c}\text { Objeto da } \\
\text { doação }\end{array}$ & frequência \\
\hline Sangue & 17 \\
Alimentos & 9 \\
Brinquedos & 8 \\
Roupas & 6 \\
Livros & 5 \\
Higiene pessoal & 2 \\
Outros & 2 \\
\hline
\end{tabular}

Fonte: Elaborado pelas autoras.

Nota-se, pelos dados da Tabela 1, a preferência pelo fomento a campanhas de doação de sangue nas escolas. Alimentos e brinquedos são os mais frequentes a seguir, mas com contagem bem menor $(9$ e 8 , respectivamente), na comparação com o objeto mais frequente das doações nessa amostra.

Dos 49 textos analisados, 17 abrangiam mais de um tipo de doação. Assim, observou-se que o segundo objeto de doação mais citado foi produto de higiene (geral ou pessoal) $(f=9)$, seguido de brinquedos $(f=6)$.
O destino das doações não foi informado em três dos textos encontrados. A Tabela 2 mostra os resultados para os dados coletados e categorizados a partir dos casos válidos para esse aspecto da análise (ou seja, 46). No entanto, como alguns casos mencionaram mais de um destino para as doações colhidas, o total das frequências é maior do que o tamanho da

amostra.

Tabela 2. Destino das doações nos textos publicados pelas escolas da amostra

\begin{tabular}{cc}
\hline Destino da doação & frequência \\
\hline Instituições voltadas à saúde & 20 \\
Instituições e comunidades carentes & 14 \\
Instituições de ensino & 9 \\
Instituições de longa permanência para & 4 \\
idosos & 4 \\
Outros destinos & \\
\hline
\end{tabular}

Fonte: Elaborado pelas autoras.

Como mostra a Tabela 2, as instituições voltadas à saúde são os destinos mais comuns das doações estimuladas pelas escolas. Foram 12 bancos de sangue citados, quatro hospitais e quatro associações e ONGs dedicadas a apoiar portadores de doenças crônicas.
Em segundo lugar, conforme a Tabela 2 , constam como mais frequentes as instituições e comunidades carentes. Estas foram assim denominadas, posto que seis casos foram qualificados dessa maneira nos textos; os demais foram a eles unidos em virtude de características como instituição de caridade, instituição de 
assistência, instituição filantrópica, entre outros termos compreendidos como pertinentes a destinos organizados em torno da carência de algum aspecto, como moradia, atendimento especializado, etc.

Com respeito às instituições de ensino, dois casos tiveram como destino das doações a própria escola. Os demais sete casos voltados para campanhas de doação direcionadas a creches. As parcerias estabelecidas para a realização das campanhas estiveram presentes em 27 casos. Em 17 deles, a parceria foi realizada com uma instituição ou órgão público, por exemplo, com prefeituras ou secretarias estaduais. Três parcerias foram de âmbito privado, uma com ONG, e seis parcerias foram de outro tipo.

Quanto aos participantes das campanhas, observou-se que em 17 delas os envolvidos eram os alunos, e em 15 foram envolvidos alunos, professores e pais. Em quatro identificou-se o envolvimento de alunos e professores; em três, alunos e pais; e em duas, apenas professores. Oito campanhas não foram categorizadas nesse aspecto em virtude da ausência de conteúdos claros para auxiliar na classificação dos participantes da ação.

O envolvimento requerido nas campanhas de doação identificadas em escolas com base nos 49 casos coletados em textos publicados na Internet foi classificado conforme segue: doar; doar e obter doadores; envolvimento amplo; obter doadores e outras ações; e outras respostas. A Tabela 3 apresenta as frequências para esses dados.

Tabela 3. Tipo de envolvimento dos alunos nas campanhas de doação referidas pelas escolas da amostra

\begin{tabular}{cc}
\hline Tipo de envolvimento & $\begin{array}{c}\text { frequênci } \\
\text { a }\end{array}$ \\
\hline Doar & 19 \\
Doar e obter doadores & 18 \\
Envolvimento amplo & 5 \\
Obter doadores e outras & 3 \\
ações & \\
Outras respostas & 4 \\
\hline
\end{tabular}

Fonte: Elaborado pelas autoras.

Assim como na análise dos destinos, as frequências relatadas na Tabela 3 totalizam mais do que o número de casos analisados. Isso ocorreu porque alguns casos apresentaram conteúdos classificados em mais de uma categoria (por exemplo, em doar e em outras respostas).
O tipo de envolvimento mais frequente nas campanhas foi o de doar $(\mathrm{f}=19)$, mas a frequência foi quase a mesma em ações que estimularam a doar e também obter doadores ( $f$ $=18)$. Na categoria envolvimento amplo, foram 
inseridos os casos em que, além do estímulo a doar e a obter doadores, realizou-se alguma das seguintes ações: apresentar a ideia da campanha, confeccionar material, entregar doações, interagir com os beneficiados e/ou divulgar a campanha.

Quanto à estratégia adotada na campanha para arrecadar o objeto em meta, a análise dos conteúdos permitiu identificar que em 40 casos a estratégia foi não competitiva, ou seja, calcava-se tão somente na entrega descompromissada do objeto pedido. Em quatro casos, a estratégia foi competitiva, realizada por meio de gincanas, por exemplo, na escola. Identificou-se três casos em que a estratégia envolvia uma premiação associada à

doação. Por fim, um caso realizou uma venda de rifa e outro utilizou o sistema de troca como estratégia para arrecadar o objeto almejado na campanha de doação.

Os valores, morais ou de outra natureza, identificados nos textos sobre as campanhas foram listados, agrupados e contabilizados. Em apenas dois casos o texto sobre a campanha de doação não trazia conteúdos que pudessem ser analisados do ponto de vista dos valores. A Tabela 4 apresenta as categorias resultantes. Cabe lembrar que a soma das frequências é maior do que o total de casos porque muitos destes trouxeram mais de um valor em seus textos.

Tabela 4. Valores identificados nos textos das campanhas de doação das escolas da amostra

\begin{tabular}{cc}
\hline $\begin{array}{c}\text { Valores identificados nas } \\
\text { campanhas }\end{array}$ & frequência \\
\hline Solidariedade & 22 \\
Ajudar & 16 \\
Senso de comunidade/grupo & 13 \\
Fazer/querer o bem a outrem & 12 \\
Valores voltados ao futuro & 6 \\
Prover emoções positivas & 5 \\
Valores para autoaperfeiçoamento & 5 \\
\hline
\end{tabular}

Fonte: Elaborado pelas autoras. 
A categoria solidariedade foi formada por conteúdos que citaram explicitamente esse aspecto, salientando o espírito de solidariedade ou a característica de ser solidário $(\mathrm{f}=22)$. A categoria ajudar também incluiu conteúdos sobre colaborar, compartilhar e apoiar, além da menção a salvar vidas. Senso de comunidade/grupo reuniu conteúdos que abordavam a união das pessoas, como no caso da integração com a sociedade, ecologia social, cidadania, participação, envolvimento familiar e atividade em grupo.

A categoria fazer/querer o bem a outrem envolveu conteúdos mais gerais abordados nas doações, ao contrário da especificidade da categoria ajudar, que remetia a comportamentos. Assim, fazer/querer o bem incluiu aspectos como bondade, caridade, beneficência, generosidade, gentileza, calor humano, causa nobre, fazer o bem, amar ao próximo e preocupação com o próximo.

Em resumo, sobre as campanhas de doação protagonizadas por escolas na amostra analisada, as notícias são publicadas nos sites das escolas, as quais em sua maioria são privadas, abrangendo os níveis de ensino infantil, fundamental e médio, e localizadas no estado de São Paulo. As doações na maioria dos casos são de sangue, destinadas a bancos de sangue ou hospitais, em parceria com instituições ou órgãos públicos. Os alunos das escolas são bastante envolvidos nas campanhas, para doar e/ou obter doadores. A estratégia majoritária nas campanhas é a não competitiva para angariar as doações, envolvendo o valor da solidariedade ao noticiarem a campanha.

\section{Discussão}

Com o tipo de estudo conduzido foi possível caracterizar ações em prol da doação publicadas na Internet realizadas por escolas. Considera-se que a escola é um lugar privilegiado para o tratamento dos temas da doação, seja de sangue, seja de algo menos custoso ao estudante, como um brinquedo ou agasalho.

Foi evidenciado que as parcerias mais constantes com a escola partem de bancos de sangue ou hospitais na direção de campanhas de doação de sangue. Esse tipo de campanha, ainda que muito relevante, não é capaz de envolver diretamente o estudante na ação. No Brasil, a idade mínima para a doação de sangue é de 16 anos, sendo que nessa idade e também aos 17 é preciso autorização dos pais (Câmara dos Deputados, 2009). Ainda assim, o projeto desenvolvido em uma escola e relatado em Menin et al. (2013) mostrou o efeito positivo das campanhas escolares sobre os pais dos alunos na adesão a esse tipo de doação.

Outro aspecto interessante notado nos resultados foi o tipo de envolvimento dos participantes nas campanhas de doação promovidas pelas escolas. Quase a totalidade da amostra dividiu-se entre doar e doar/obter doadores. Em termos de envolvimento, pode-se considerar que o segundo tipo está em um patamar mais avançado com relação ao primeiro, posto que exige que o estudante não apenas motive a si para doar, mas que ele motive a outrem para tal também. Dessa forma, campanhas de doação nas escolas podem atentar para esse aspecto a partir do momento em que 
notarem que os alunos de fato assimilaram os aspectos básicos sobre a campanha, estão motivados para agir e têm condições para tal.

Ainda sobre essa questão de obter doadores, interessante notar que a maior parte das campanhas se dividiu entre envolver os alunos e envolver alunos, professores e pais. Há uma ampla literatura publicada no Brasil mostrando dados de intervenções em escolas envolvendo toda a comunidade escolar e obtendo melhores resultados. Um exemplo dessa literatura está em alguns dos projetos de educação em valores relatados em Menin et al. (2013). Além disso, o trabalho de van Ijzendoorn et al. (2010) mostrou a importância de um adulto servir como exemplo e incentivador para a criança diante de situações em que ela deve tomar uma decisão sobre fazer uma doação para uma instituição de caridade. Ao envolver pais e professores nas campanhas, ao lado dos alunos, provavelmente haveria mais adesão por parte destes últimos.

As instituições e comunidades carentes como o segundo destino mais identificado nas campanhas é um resultado que se aproxima do estudo de Ongley et al. (2014). Esses autores destacaram o papel dos sentimentos morais no processo decisório das crianças sobre ações de doar para pares pobres. Simpatia e culpa exerceriam interferência no processo decisório. De fato, ao apelar às necessidades das pessoas (às suas carências) oportuniza-se à benevolência uma forma de se sobrepor a tendências egoístas. Além disso, os estudos de La Taille (2006) sobre a gênese da generosidade na infância $e$ a intervenção educativa de Figueiredo e Comino (2014) com a conscientização da doação de sangue em menores de 16 anos unem-se para fortalecer a pertinência de se tratar da doação, de qualquer tipo, no ensino fundamental.

Sobre os valores mais citados nos conteúdos analisados, todos destacam aspectos associados à benevolência: solidariedade, ajudar, senso de comunidade, fazer o bem, querer o bem. Souza e Freitas (2019) também identificaram a solidariedade como o valor mais citado na revisão de literatura sobre doação.

Ser solidário, ajudar e fazer o bem remetem à virtude da generosidade. A esse respeito cabe mencionar a visão de ComteSponville (2009) sobre essa virtude. Segundo esse autor, "a generosidade é a virtude do dom" (p.97), o que vai ao encontro de o que já se vem argumentando no presente trabalho. Por isso a generosidade foi tão presente nos textos sobre as campanhas de doação em escolas, conforme mostrou a análise sobre a amostra investigada.

Outro aspecto de destaque foi a valorização do senso de comunidade nos conteúdos das notícias das campanhas. Sobre esse aspecto, cabe lembrar que, em Psicologia Moral, tanto os estudos dedicados à justiça quanto os focalizados na benevolência ressaltam a importância da empatia para que o comportamento moral de fato ocorra. A título de ilustração, a teoria do desenvolvimento do raciocínio moral de Lawrence Kohlberg (Biaggio, 1997), que focaliza no raciocínio voltado para as questões de justiça, considera que a empatia é fundamental para o avanço de um estágio menos evoluído para um mais evoluído. No estágio 1, por exemplo, as justificativas para as ações morais são calcadas em obediência sem questionamentos ou em 
temor a punições. Portanto, o sujeito nesse estágio não se conecta à perspectiva de outrem senão à própria, demonstrando ausência de inclinações empáticas.

De outro lado, há os estudos de Godbout (1992), que argumenta que doar pressupõe laços interpessoais. Segundo esse autor, a família é o lugar onde se aprende o dom (o fenômeno por trás do ato de doar). Enquanto elo social, o dom cria um sentimento de obrigação, posto que cada doador pensa que recebe mais do que dá. Por essa razão, trata-se de uma desigualdade alternada, um sistema dinâmico, sempre em movimento. Portanto, o senso de comunidade é fundamental ao dom; para o autor, o dom está na raiz dos laços sociais. Assim, pelo papel que a família exerce no desenvolvimento do sentimento do dom, cabe envolver os pais dos alunos nas campanhas de doação protagonizadas por escolas. Em complemento, por meio de projetos desse tipo, o laço entre a escola e a família se estreita, como argumentam Polonia e Dessen (2005).

Ainda que a maioria das ações tenha sido realizada por intermédio de estratégias não competitivas e sem envolver retribuição, ou seja, no espírito mesmo da generosidade, foi interessante notar os casos em que a estratégia da campanha diferiu. Em três casos a escola ofereceu uma espécie de retribuição ou premiação pela doação feita; em um caso, uma escola realizou uma rifa para angariar doações. Mesmo que identificadas como campanhas de doação, esses casos não estão em consonância com o espírito da solidariedade e da generosidade. São casos em que há uma clara troca em andamento, sem, portanto, custos pessoais para o doador, descaracterizando-o como tal. A intenção das campanhas é positiva, mas os mecanismos de motivação utilizados passam ao largo de o que significa o altruísmo no contexto em que ele deveria se sobrepor: o contexto de uma doação.

A maioria das escolas identificadas foi da rede privada, o que não é surpreendente, considerando que escolas desse tipo têm mais recursos humanos e materiais para maior envolvimento nas redes sociais e publicações via Internet. Outro aspecto que chama a atenção é que pouco mais da metade das campanhas ocorreu entre os meses de setembro e dezembro. Nessa época, concentram-se datas comemorativas como Dia da Criança, Dia do Idoso, Dia Nacional do Livro e Natal - datas que movimentam as escolas com atividades diversas, servindo também de motivação para campanhas de doação.

\section{Considerações finais}

O presente trabalho vem a contribuir para o limitado corpo de conhecimentos disponível sobre doação no país. Mais especificamente, caracterizou o modo como as escolas veicularam os conteúdos sobre as campanhas de doação que protagonizaram. Foi possível conhecer características das escolas, das campanhas e dos valores nestas envolvidos.

A principal limitação do estudo está na pequena amostra analisada, ainda que tenha envolvido 18 estados brasileiros. Os próximos estudos podem ser delineados para contatar diretamente as escolas e obter dados mais detalhados sobre seus procedimentos adotados 
nas campanhas realizadas pelas instituições. Claramente uma limitação do trabalho é o foco nas publicações na Internet, o que pode ter desconsiderado campanhas de doação conduzidas por muitas escolas públicas. Tomado o caráter exploratório do estudo, no entanto, considera-se válido pelos dados encontrados e discutidos. Estudos futuros podem contatar diretamente escolas públicas e buscar coletar informações sobre suas atividades no tema da doação.

A contribuição dessa pesquisa pode estar em fornecer orientações básicas para o trabalho com campanhas de doação em escolas. As recomendações a seguir são decorrentes dos resultados e discussão apresentados:

- envolver não apenas alunos do ensino médio, mas também do ensino fundamental. A propósito, os alunos mais velhos podem ser estimulados e orientados a se envolver com os mais novos nas atividades, como tutores ou pares;

- abordar doações de objetos concretos e com destino especificado. A título de exemplo, doações de brinquedos a instituições que abrigam crianças e doações de livros a presídios são possíveis e pouco custosas aos alunos e à comunidade. Parcerias com órgãos governamentais podem facilitar contatos e viabilizar a entrega das doações;

- focalizar não apenas em valores solidários, mas no valor do senso de comunidade, do autoaperfeiçoamento e da visão de futuro;

- utilizar estratégia não competitiva, envolvendo alunos, professores e pais. O entendimento amplo de Godbout (1992) sobre o dom pode ser explicitado, posto que alunos, pais e professores, em uma campanha de doação, estão doando tempo e dedicação à causa. Assim, fica mais evidente como o dom perpassa todo o processo de uma campanha;

- inserir o tema da doação no projeto pedagógico da escola, destacando-o no trabalho com docentes, alunos e familiares, e realizando atividades em diferentes momentos do ano letivo;

- avançar a partir da posição de doador para a de obter doadores. Estimular os alunos a serem multiplicadores da causa é uma direção mais avançada do que tão somente torná-los doadores na campanha.

Espera-se que o presente trabalho incentive novas pesquisas no tema. Em especial, que estimule a realização de campanhas de doação em escolas e outros contextos educativos, como no caso das universidades e faculdades. Doar é uma ação altamente valorizada pelas sociedades; o que falta é mais dedicação a promovê-la e concretizá-la.

\section{Referências}

Biaggio, A. M. B. (1997). Kohlberg e a "Comunidade Justa": promovendo o senso ético e a cidadania na escola. 
Psicologia: Reflexão e Crítica, 10(1), 47-69.

Doi:

http://dx.doi.org/10.1590/S010279721997000100005.

Biaggio, A. M. B. (1999). Universalismo versus relativismo no julgamento moral.

Psicologia: Reflexão e Crítica, 12(1), 5-20.

Doi: https://doi.org/10.1590/S0102-

79721999000100002 .

Brandão, T., Mota, N., \& Pizzolato, A. (2016). Conhecimento de estudantes de ensino médio da rede particular e pública a respeito de transplante e doação de órgãos e tecidos. Revista Amazônia: Science and Health, 4(1), 2-9. Doi: http://dx.doi.org/10.18606/23181419/amazonia.sci.health.v4n1p2-9.

Câmara dos Deputados (2009). Legislação Brasileira sobre Doação de Órgãos Humanos e de Sangue (2a ed.). Brasília: Câmara dos Deputados/Edições Câmara. Recuperado em 20 agosto, 2018, de http://bd.camara.gov.br/bd/bitstrea $\mathrm{m} /$ handle/bdcamara/747/doacao or gaos 2ed.pdf? sequence $=3$.

Comte-Sponville, A. (2009). Pequeno tratado das grandes virtudes (2a ed., E. Brandão, Trad.). São Paulo: Editora WMF Martins Fontes.

Eisenberg, N., Spinrad, T. L., \& Morris, A. S. (2014). In M. Killen e J. G. Smetana (Eds.). Empathy-Related Responding in Children: Handbook of Moral Development (pp. 184-207). New York: Psychology Press.

Fabes, R. A., \& Eisenberg, N. (1998). MetaAnalyses of Age and Sex Differences in Children's and Adolescents' Prosocial Behavior. Recuperado em 6 março, 2018, de http://www.public.asu.edu/ rafabes Lmeta.pdf.

Figueiredo, R., \& Comino, L. (2014). Doação de sangue: rompendo barreiras com alunos do ensino fundamental. Interagir: Pensando a Extensão, 17/18/19, 53-56. Doi: https://doi.org/10.12957/interag.201 4.13566.
Godbout, J. (1992). O espirito da dádiva. Lisboa: Instituto Piaget.

La Taille, Y. (2006). A importância da generosidade no início da gênese da moralidade na criança. Psicologia: Reflexão e Crítica, 19(1), 9-17. Doi: https://doi.org/10.1590/S010279722006000100003.

Menin, M. S. de S., Bataglia, P. U. R., \& Zechi, J. A. M. (Orgs.). (2013). Projetos bem-sucedidos de Educação em valores. São Paulo: Cortez.

Moraes, M., Gallani, M., \& Meneghin, P. (2006). Crenças que influenciam adolescentes na doação de órgãos. Revista da Escola de Enfermagem da USP, 40(4), 484-492. Recuperado em 6 março, 2018, de http://www.ee.usp.br/reeusp/upload Lpdf/280.pdf.

Nogueira, M. et al. (2016). Conhecimentos e posicionamentos de adolescentes sobre doação de órgãos antes e após uma ação educativa. Revista de Enfermagem e Atenção à Saúde, 5(2), 57-72. Doi: https://doi.org/10.18554/reas.v5i2.1 $\underline{560}$.

Ongley, S., Nola, M., \& Malti, T. (2014). Children's Giving: Moral Reasoning and Moral Emotions in the Development of Donation Behaviors. Frontiers in Psychology, 5, article 458. Doi: https://doi.org/10.3389/fpsyg.2014.0 $\underline{0458}$.

Polonia, A., \& Dessen, M. (2005). Em busca de uma compreensão das relações entre família e escola. Psicologia Escolar e Educacional, 9(2), 303-312. Recuperado em 6 março, 2018, de http://pepsic.bvsalud.org/scielo.php? script $=$ sci arttext\&pid $=S 1413$ $85572005000200012 \& \ln g=p t \& t \operatorname{lng}=p$ t.

Saldaña, J. (2011). Fundamentals of Qualitative Research: Understanding Qualitative Research. New York: Oxford University.

Schirmer, J., Leite, R., Roza, B., Silva, A., Fujinami, T., Lemos, M., \& Kian, F. (2007). Doação de órgãos e tecidos: o que 
sabem os estudantes do ensino médio?.

Einstein, 5(3), 213-219. Recuperado em 6

março, 2018, de

http://apps.einstein.br/revista/arquiv

os/PDF/423-

einstein $\% 205 \% 203 \% 201 \% 20$ online $\%$

20 artigo $\% 20$ portugues213-219p.pdf.

Souza, L. K. de, \& Freitas, L. (2019). A doação

na literatura científica nacional:

contribuições à Psicologia Moral. Psico-

USF, 24(1), 159-171. Doi:

http://dx.doi.org/10.1590/1413-

82712019240113.

Van Ijzendoorn, M., Bakermans-Kranenburg,

M., Pannebakker, F., \& Out, D. (2010). In

Defense of Situational Morality: Genetic,

Dispositional, and Situational

Determinants of Children's Donating to

Charity. Journal of Moral Education, 39(1),

1-20. Doi:

https://doi.org/10.1080/0305724090

3528535.

Recebido em: 7/3/2018

Aprovado em: 21/11/2018 